\title{
Peyzaj Mimarlığı Eğitiminde Doğaya Öykünme Yaklaşımının Yaratıcılık Üzerindeki Etkisi
}

\author{
Tuğba DÜZENLi ${ }^{1 *}$, Elif Merve ALPAK²
}

öz

Peyzaj mimarlığı; insanların ihtiyaç ve istekleri doğrultusunda açık mekânlar tasarlayan bir disiplindir. Peyzaj mimarları açık mekânları tasarlarken öncelikle kullanıcı odaklı, birbirinden farklı ve yaratıcı tasarımlar ön plana çıkarmalıdır. Bu nedenle peyzaj mimarlığı eğitiminde öğrencilere, tasarım ve yaratıcılık becerisi kazandırabilecek yaklaşımların öğretilmesi gerekmektedir.

Bu çalışmada, Karadeniz Teknik Üniversitesi Peyzaj Mimarlığı 4. Yarıyılda verilen 'Doğal Yapılar ve Tasarım' seçmeli dersinin, öğrencilerin yaratıcılığını geliştirmedeki etkisini belirlemek amaçlanmıştır. Dersin asıl amacı öğrencilere, problemlere yönelik doğada sonsuz sayıda, yol gösterici, mükemmel tasarımlar olduğunu ve bunlardan esinlenerek işleve uygun yaratıcı tasarımlar yapabileceklerini öğretmektir. Böylece günümüzün en büyük problemlerinden biri olan birbirinin aynı olan ve bir kimliği olmayan açık mekânların tasarlanma nedenleri temelden öğrencilere öğretilmiş olur ve bu sorunun çözümüne yönelik tasarımlar yapmaya teşvik edilirler.

Bu bağlamda, 'Doğal Yapılar ve Tasarım' seçmeli dersini alan (30 kişi) ve dersi almayan (30 kişi) öğrencilere, proje derslerinde yaratıcı tasarımlar yapabilmeleri ile ilgili hazırlanan bir anket yapılmıştır. Böylelikle dersi alan öğrenciler ile almayan öğrencilerin yaratıcılık düzeylerinde farklılık olup olmadığı belirlenmeye çalışılmıştır. Sonuçta doğaya öykünme yaklaşımını bilen öğrencilerin, bilmeyen öğrencilere göre yaratıcı tasarımlar yapmakta daha az zorlandıkları ortaya konmuştur.

Anahtar Kelimeler: Doğaya öykünme, peyzaj mimarlığı eğitimi, yaratıcılık, tasarım eğitimi

\section{The Influence of Natural Inspiration Approach on Creativity In Landscape Architecture Education}

\begin{abstract}
Landscape architecture is a discipline that designs open spaces for people's needs and preferences. When designing open spaces, landscape architects must first focus on user-focused, distinctive and creative designs. For this reason, landscape architectural education should be taught to students about design and creativity skills.

In this study, it is aimed to determine the effect of the 'Natural Structures and Design' course to improve the creativity of the students; that is taught in the 4th semester during the education in the Department of Landscape Architecture in Karadeniz Technical University is examined. The main aim of the course is to teach the students that there is an infinite number of guiding, perfect designs for the problems in the nature, and that they can inspire and design appropriate creative designs. Thus, the reasons for designing open spaces that are one of the greatest problems of ours, which are the same and which are not an identity, are taught to students on a basis and encouraged to design solutions to this problem.

In this context, a questionnaire was prepared for students who did not take the 'Natural Structures and Design' elective course (30) and those who did not take the course (30) to make creative designs in project courses. Thus, it has been tried not to determine whether there is any difference in the creativity levels of the students taking the course or not. As a result, it was revealed that students who know the nature emulation approach are less able to make creative designs according to the students who do not know.
\end{abstract}

Keywords: Inspiration from nature, landscape architecture education, creativity, design education

\footnotetext{
${ }^{1}$ Karadeniz Teknik Üniversitesi, Orman Fakültesi, Peyzaj Mimarlığı Bölümü, tugbaduzenli@gmail.com

${ }^{2}$ Karadeniz Teknik Üniversitesi, Orman Fakültesi, Peyzaj Mimarlığı Bölümü

*ilgili yazar / Corresponding author: Tuğba DÜZENLi , tugbaduzenli@gmail.com

Gönderim Tarihi: 16.11 .2016

Kabul Tarihi: 13.12.2016
} 


\section{GíRiş}

Mühendislik, kent bölge planlama, güzel sanatlar, doğa bilimleri, mimarlık, peyzaj mimarlığı gibi pek çok disiplinin temeli, tasarıma dayanmaktadır. Düşünce dünyasındaki gelişmelere bağlı olarak, tasarım süreci olgusu zaman içinde farklı yaklaşım ve açıklamalarla ele alınmıştır. Aynı çerçevede ön plana çıkan bir başka konu da yaratıcılık kavramıdır. Yaratıcılık kavramı ve tasarım süreci aynı bütünün içinde farklı boyut ve yönleri ifade eden kavramlar olarak kabul edilir (Kahvecioğlu, 2001).

Tasarım kavramı ile ilgili olarak birçok farklı tanım ve yaklaşım bulunmaktadır. Birçok araştırmacıya göre tasarım bir problem çözme sürecidir, bazı araştırmacılara göre karar verme, kimilerine göre ise deneme-yanılma sürecidir (Önal, 2011). Yani tasarım genellikle; "bir faaliyet için gerekli olan şemaların veya planların hazırlanması süreci" olarak tanımlanırken, "yaratıcı sürecin kendisi" olarak da ele alınabilir. Tasarım sürekli problem çözme sürecinin bir parçasıdır (Newel ve Simon, 1972). Ve bu doğrultuda tasarım, "belirsizlikler içerisinde karar vermek" (Asimow, 1962), "çeşitlilik azaltmak" (Best, 1969), "fiziksel bir yapının doğru fiziksel bileşenlerini bulmak" (Alexander, 1964) gibi çeşitli tanımlarla ifade edilmiştir. Bayazıt (1994) en temel tanımı ile tasarlama bir plan ya da eskiz yapmak üzere zihinde canlandırmak, biçim vermek ya da üretilerek zihinde canlandırılan bir plan ya da bir şeydir demiştir (Önal, 2011). Bir sonucu hazırlayan adımların ortaya konulduğu zihni bir proje ya da şemadır. Bunları yapabilmek için bir sürece ihtiyaç vardır. Bu tasarım süreci, tasarımcının algılama-düşünme-ifade etme ve kullanılan görsel-sözel araçlarla gerçekleştirdiği aktiviteler bütünüdür. Bu süreçte kullanılan araçlar; süreci, bir fikrin ifadesi olan ürünü ve onun algısını etkiler (Anderson, 2011). Dolayısıyla tasarlama süreci, zihinsel düşünce gücünü, tüm duyuların çevreden topladığı verileri ve doğuştan gelen yetenekleri bir bütün olarak sentezlendiği bir etkinliktir.

Ancak tasarımcının bu süreç sonunda, belirlediği sorun karşısında en iyi çözümü üretecek yaratıcı ve orijinal tasarımlar yaratması beklenmektedir. Bunun için yaratıcı düşünebilen, yaratıcılığı analitik düşünme ile bütünleştirebilen, yenilik yapabilen, problem çözebilen, insanların eğitim kurumlarında yetiştirilmesi gerekmektedir. Öztürk'e (2010) göre tasarım eğitimi, tasarlanmaya muhtaç bir bilinmezdir. Bu nedenle tasarım sürecinin başında tasarımcının izleyeceği yolu belirlemesi, nasıl bir düşünme biçimi ve hangi yöntem ile başlayacağı oldukça önemli bir noktaya işaret etmektedir (Melikoğlu Eke, 2015). Peyzaj mimarlığı eğitimi de, karar üretme, arazi biçimleme, mekân düzenleme ve insan aktivitelerini organize etmektir şeklinde tanımlanmaktadır (Rodiek ve Steiner, 1998) ve farklı disiplinlerden gelen kavramları bünyesinde barındıran çok yönlü bir meslek olduğundan, eğitiminde farklı sistem ve bileşenlerin birbirlerine entegre edilmesi gereklidir. Yaratıcı tasarım ürünleri oluşturmada, doğaya öykünme yaklaşımı tasarım sürecine dahil edilerek (Kowaltowski vd., 2010) öğrencilerin fikirlerini biçime dönüştürmesinde yaşadıkları zorlukların üstesinden gelmeleri sağlanabilmektedir.

Bu nedenle, Karadeniz Teknik Üniversitesi (KTÜ) Peyzaj Mimarlığı Bölümünde 4. Yarıyıl 'Doğal Yapılar ve Tasarım' seçmeli dersi kapsamında, öğrencilerin özgün tasarımlar yapabilmeleri için yaratıcılıkta yol gösterici ve esin kaynağı olan doğaya öykünme kavramının tasarım sürecine nasıl entegre edileceği öğretilmektedir. Bu çalışmada da, doğaya öykünme dersini alan ve almayan öğrencilerin, fikirlerini yaratıcı tasarımlara dönüştürmedeki farklılıkları ortaya konmaya çalışımıştır.

\subsection{Yaratıcılık-Doğaya Öykünme-Tasarım Süreci İlişkisi}

İnsanın tüm duyuşsal ve düşünsel becerilerini kapsayan bir kavram olan 'yaratıcılık ve yaratıcı düşünce', insanlık tarihi kadar köklü bir gelişim sürecinden geçerek bugünlere 
gelmiştir (Özkan vd., 2016). Webster (1999), yaratıcılığı, bir yaratma, yeni bir şey, biçim veya aşama oluşturma, bir eylem veya davranışın beraberinde getirdiği özgün bir üretme olarak açıklamaktadır (Kahvecioğlu, 2001). “Tasarımda yaratıcılık” çok yönlü düşünebilme, empoze edilmiş düşünce çizgisinin dışına çıkma ve diğerlerinden farklı düşünebilmedir; problemlerin çözümüne birçok farklı açıdan yaklaşabilme, yeni bir ilişki kurma veya var olan düşünceler arasında ilişkiyi yeniden kurgulayabilme, rahat-çabuk-bağımsız ve akıcı düşünebilme ve tüm bunları tasarıma yansıtabilmedir (Uzunarslan ve Polatkan, 2011). Yani yaratıcılık "yeni ve alışılmamış bir şeyin ortaya konması" süreci olarak tanımlanmaktadır. Bu süreç boyunca farklı bir yol izleme, kalıpların dışına çıkma, bilinmeyene dalmaktan çekinmeme, fikirler arasındaki ilişkilerde başkalarının göremediği noktaları görebilme, yeniliklere açık olma gibi düşünce süreçleri ve kişilik özellikleri vurgulanır (Öncü, 2003). Aynı zamanda yenilik, yararlıık, orjinallik oluşturma (Ayıran, 1983), yeniden tanımlama, çözümleme ve sentez (Yavuzer, 1989), zihinde yeni ve farklı tekrarlar oluşturarak, ürüne dönüştürme (Abra, 1997) gibi kavramlarla, yaratıcılığa ait ölçütler belirlemeye çalışılmıştır (Kahvecioğlu, 2001). Aynı zamanda yaratıcılığı geliştirme süreçlerini ele alan araştırmacılar, yaratıcılığın doğuştan gelen bir yetenek olduğu gibi eğitim ile doğru zamanda doğru bilgiyi vererek de öğretilebilir ve geliştirilebilir olduğunu savunmaktadırlar (Apaydın, 2015; Weisberg, 2004) ve hayal gücünün, yaratıcılığın önceliği olduğunu söylemektedirler (Çubukcu and Gökçen Dündar, 2007).

Tasarım sürecinde, yaratıcılığın nasıl geliştirilebileceği ya da yaratıcılığın nasıl öğretilebileceği tasarım eğitiminin önemli bir problemidir (Casakin, 2007; Çubukcu ve Dündar, 2007). Özellikle tasarım eğitiminin ilk yıllarında öğrencilerin zihinlerinde kurguladığı tasarımı, eskiz üzerine aktarmaları oldukça zordur. Çünkü tasarım her ne kadar somut bir sonuç olsa da tasarımcıyı bu sonuca götüren süreç soyuttur. Özellikle eğitimin başlangıç döneminde olan öğrencilerin tasarım bilgisi, görgüsü yetersiz olduğu için bu soyut süreci somuta dönüştürmekte zorlanmaktadırlar. Yapılan araştırmalar hayal gücünü geliştirmede ve biçim üretme konusunda zorluk çeken öğrencilere, doğaya öykünmenin yardımcı olabileceğini savunmaktadırlar.

\subsection{Doğaya Öykünme}

Doğa hem öğreticidir, hem de her anlamda eğitici, ilham verici, destekleyici bilgiler içerir. Bu nedenle tüm tasarım disiplinlerinin (mimarlar, iç mimarlar, peyzaj mimarları, şehir bölge planlamacıları endüstriyel tasarımcılar vb.) doğadan öğreneceği çok şey vardır. Çünkü doğaya öykünme, yeni bilgilerin edinilmesini destekleyen ve öğrenmeye yardımcı olan bir bilişsel süreçtir (Hofstadter, 2001; Casakin ve Timmeren van, 2015). Tasarımcılar doğaya öykünerek, aynen yorumlayarak ve çeşitli mecazlar yükleyerek (Emmanuel ve Le Duc, 1990), tasarım problemini daha kolay (Dunbar ve Blachette, 2001; Ball vd. 2004; Ball ve Christensen, 2009) ve yaratıcı bir şekilde çözümlemişlerdir.

Doğaya öykünme, doğadan tasarıma aktarılacak konuya kapsamlı bir bakış açısıyla gerçekleşir. Burada birebir benzetimden uzak, doğadaki örneğin taklit edilmesi, form, işlev ya da sürecin değerlendirilmesi değil de, çağrışım yapılarak fikir aktarılması söz konusudur. Yani öykünme ya da taklit etme; doğa biçimleri ve yasalarının sanat için bir model oluşturması olarak açıklanır ve bir kaynaktan öğrenme, esinlenme, yorumlama bir şeylerin yansıması olarak da ele alınır (Tunalı, 2002; Ziss, 1984; Chui ve Shu, 2007).

Doğaya öykünmenin çeşitli şekillerini ele alan araştırmalar taklidin iki türünü tanımlamışlardır (Arslan ve Sorguç, 2007; Hagan, 2001; Kellert, 2005). Doğaya öykünmenin ilk şekli doğal objenin formunun alınıp biçimsel kaygılarla ve bir analojiyle yapıya aktarılması diğeri ise yapılaşmada gözlemlenen oluşum biçimin (malzeme, form ve strüktürünün) deneysel verilerle mimari forma dönüştürülmesidir (Arslan ve Sorguç, 2007). Doğaya öykünme ve tasarım ilişkisine yönelik olan iki temel yaklaşım (Biomimicry Guild, 2007), mimarlık alanına üç seviyede incelenerek taşınabilir: organizma, davranış ve ekosistem. Organizma 
seviyesinde, bitki ya da hayvan gibi belirli bir organizmanın bütününü ya da bir kısmını içerir. İkinci seviye davranışın taklidi üzerinde dayalıdır ve organizmanın davranışıyla ya da içinde bulunduğu çevre ile olan etkileşimi ile ilgilidir. Üçüncü seviyede ise, bütün bir ekosistemin ve ana ilkelerinin taklit edilmesiyle gerçekleşir. Sonuç olarak; doğadan öğrenmenin, doğaya öykünmenin salt analojinin ötesinde somut verilere dayandırılarak ve süreci anlamaya dönük yapılması gereken hem biçimsel hem işlevsel bir süreçtir. Öykünme seviyesi, tasarımın nasıl göründüğü (biçim), neden yapıldığı (malzeme), nasıl yapıldığı (yapı), nasıl çalıştığı (süreç), ne yapabildiği (işlev) gibi soruları yanıtlayabilen özellikte alt sınıflardan oluşmaktadır.

Tasarım öğrencileri için doğaya öykünme, hem biçimsel hem de işlevsel açıdan sonsuz çeşitlilikte problem çözümü kombinasyonuna ilişkin hazır çözümler demektir. Çözümsüz olduğu düşünülen pek çok konuda öğrenci doğayı gözlemleyerek doğadaki mevcut çözümlerden faydalanabilir. Bu nedenle peyzaj mimarlığı eğitiminde de doğaya öykünme yaklaşımının öğrencilere kazandırılması önemlidir.

\section{MATERYAL ve YÖNTEM}

KTÜ Peyzaj Mimarlığı Bölümü 4. Yarıyıl "Doğal Yapılar ve Tasarım” seçmeli dersinde öğrenciler, öncelikle doğaya öykünme, mimesis, biomimesis, organik mimari gibi konularda bilgilendirilirler. Daha sonra dünyadaki öykünme yaklaşımı örnekleri ve mimarların bu konudaki görüşleri, öykünme çeşitleri ve faydaları ele alınır. Dersin sonraki aşamalarında dersi alan 30 öğrenciden doğadan örnek seçmeleri ve bu örneği biçimsel-işlevsel açıdan analiz ederek bir konsept oluşturmaları istenir (Şekil 1).

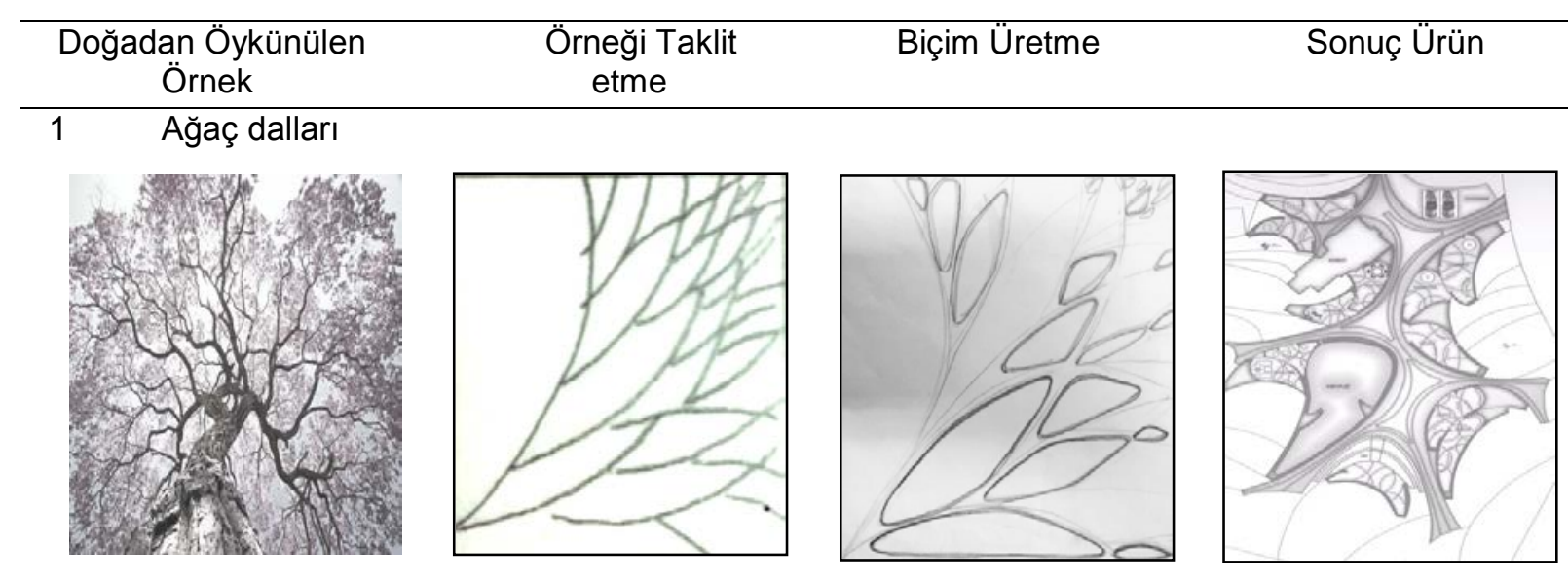

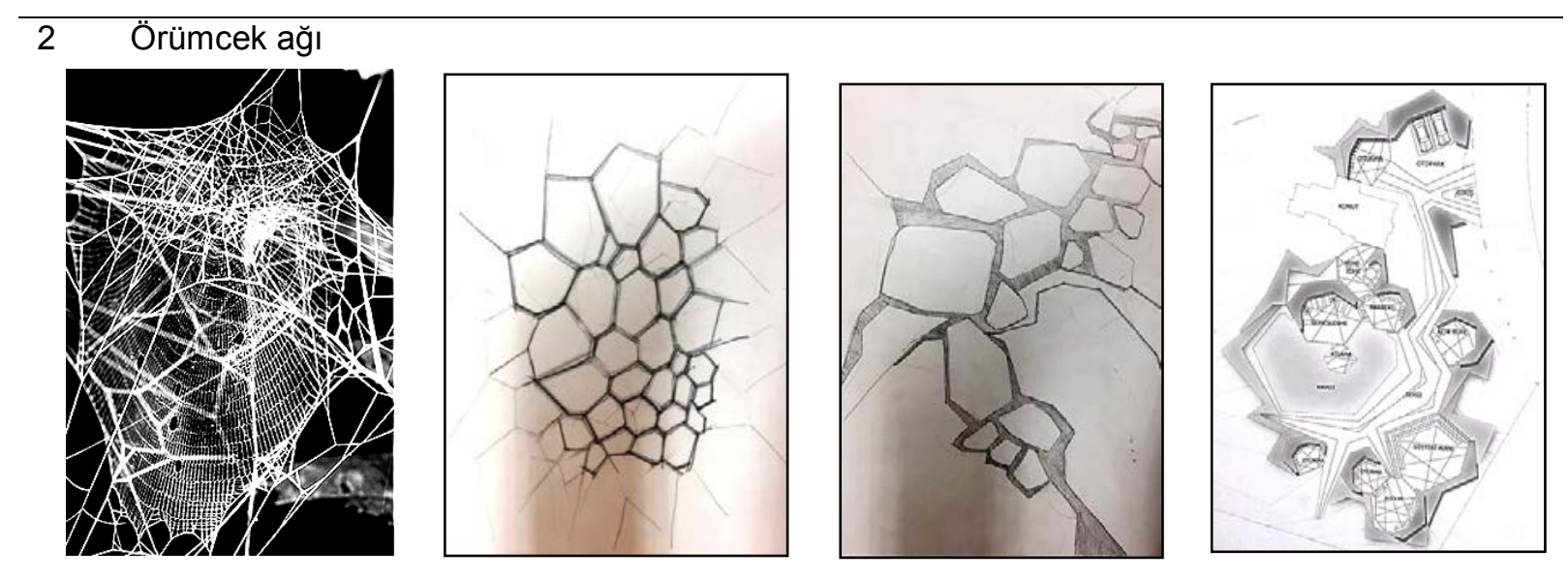

Şekil 1. Öğrenci çalışmaları 
Dönem sonunda, doğaya öykünme yaklaşımını bilip Çevre Tasarım Proje (ÇTP 4) dersinde, tasarımlarını bu yaklaşıma göre ilerleten 30 öğrenci ile bu dersi almayan 30 öğrenciye yaratıcı-özgün tasarımlar üretme ile ilgili hazırlanan bir anket yapılmıştır, ankette $5 \mathrm{li}$ değerlendirme skalası kullanılmıştır (Çizelge 1). Ankette elde edilen verilerin ortalaması alınarak mean değerleri bulunmuş, verilere independent $T$ testi ve Korelasyon analizi uygulanmıştır. Böylelikle doğaya öykünme dersinin, öğrencilerin yaratıcı-özgün tasarımlara ulaşmadaki katkısı ortaya konmuştur.

Çizelge 1. Anket soruları

Soru 1. Yaratıcı-özgün düşüncelerimi eskize aktarmada zorlanmıyorum.

1.Kesinlikle katılmıyorum 2. Katılmıyorum 3. Olabilir 4. Katılıyorum 5. Kesinlikle katılıyorum

Soru 2. Tasarım yaparken, probleme uygun biçim üretmekte zorlanmıyorum.

1.Kesinlikle katılmıyorum 2. Katılmıyorum 3. Olabilir 4. Katılıyorum 5. Kesinlikle katılıyorum

Soru 3. Tasarım yaparken probleme uygun yeni ve alışılmamış bir çözüm bulmakta zorlanmıyorum.

1.Kesinlikle katılmıyorum 2. Katılmıyorum 3. Olabilir 4. Katılıyorum 5. Kesinlikle katılıyorum

Soru 4. Tasarım sürecinde çok yönlü düşünebiliyorum.

1.Kesinlikle katılmıyorum 2. Katılmıyorum 3. Olabilir 4. Katılıyorum 5. Kesinlikle katılıyorum

Soru 5. Tasarıma başladıktan sonra, çıkmaza girersem yeni ve farklı bir çözüm üretmekte zorlanmıyorum.

1.Kesinlikle katılmıyorum 2. Katılmıyorum 3. Olabilir 4. Katılıyorum 5. Kesinlikle katılıyorum

Soru 6. Tasarım sürecini rahat-çabuk-akıcı bir şekilde tamamlayabiliyorum.

1.Kesinlikle katılmıyorum 2. Katılmıyorum 3. Olabilir 4. Katılıyorum 5. Kesinlikle katılıyorum

Soru7. Tasarım süreci sonunda yaratıcı ve özgün tasarımlar yapmakta zorlanmiyorum.

1.Kesinlikle katılmıyorum 2. Katımıyorum 3. Olabilir 4. Katılıyorum 5. Kesinlikle katılıyorum

\section{BULGULAR}

\subsection{Doğaya öykünme dersini alan ve almayan öğrencilerin cevaplarına ilişkin bulgular}

Bu aşamada dersi alan ve almayan öğrencilerin yaratıcılık ile ilgili sorulara verdiği cevaplar arasında farklııklar olduğu belirlenmiştir. Bu sonuçlara göre dersi alan öğrencilerin yaratıcılık düzeylerinin daha yüksek olduğu, dersi almayan öğrencilerin yaratıcılık düzeylerinin ise daha düşük düzeyde olduğu görünmektedir (Çizelge 2).

\begin{tabular}{llc} 
Çizelge 2. Doğaya öykünme dersini alan-almayan öğrencilerin yaratıcılık düzeyleri \\
\hline \multirow{2}{*}{ Eskize aktarma } & Öğrenci & Ortalama \\
& Dersi alan & 4,53 \\
Biçim üretme & Dersi almayan & 2,03 \\
& Dersi alan & 4,37 \\
Probleme uygun yeni çözümler bulma & Dersi almayan & 2,00 \\
& Dersi alan & 4,43 \\
Çok yönlü düşünme & Dersi almayan & 2,53 \\
& Dersi alan & 4,20 \\
Çıkmaza girdiğinde yeni çözüm üretme & Dersi almayan & 2,63 \\
& Dersi alan & 4,10 \\
Tasarım sürecini rahat-çabuk-akıcı & Dersi almayan & 2,50 \\
tamamlama & Dersi alan & 4,13 \\
Yaratıcı-özgün tasarım üretme & Dersi almayan & 2,33 \\
& Dersi alan & 4,43 \\
& Dersi almayan & 2,20 \\
\hline
\end{tabular}


Doğaya öykünme dersini alan ve almayan öğrencilerin yaratıcı fikir üretme ve bunları eskiz üzerine aktarma konusunda yaşadıkları farklılıkların istatistiksel olarak anlamlı olup olmadığını belirlemek için SPSS (v. 17.0) kullanılarak Independent-Samples $T$ testi yapılmıştır. Testin sonuçları doğuya öykünme dersini alan ve almayan öğrencilerin yaratıcı ürünler üretmede istatiksel olarak farklılıklar yaşadığını göstermektedir $(p<0.01)$ (Çizelge 3). Dolayısıyla doğaya öykünme yaklaşımının, öğrencilerin yaratıcılığını geliştirme konusunda önemli bir faktör olduğu sonucu ortaya çıkmaktadır.

Çizelge 3. Öğrencilerin yaratııılık düzeylerindeki farklılıkların değerlendirilmesi

\begin{tabular}{lccc}
\hline & $\mathrm{F}$ & $\mathrm{df}$ & Sig. (2-tailed) \\
Eskize aktarma & 6,034 & 58 &, 000 \\
Biçim üretme & 3,680 & 58 &, 000 \\
Probleme uygun yeni çözümler bulma & 4,737 & 58 &, 000 \\
Çok yönlü düşünme & 2,357 & 58 &, 000 \\
Çıkmaza girdiğinde yeni çözüm üretme &, 162 & 58 &, 000 \\
Tasarımı rahat-çabuk-akıcı tamamlama & 5,003 & 58 &, 000 \\
Yaratııı-özgün tasarım üretme & 7,061 & 58 &, 000 \\
\hline
\end{tabular}

\subsection{Yaratıcı tasarımlar üretmeye ilişkin bulgular}

Yaratıcı-özgün tasarımlar üretme ile kavramlar (eskize aktarma, biçim üretme, yeni çözümler bulma, çok yönlü düşünme, tasarım sürecini rahat-çabuk-akıcı tamamlama) arasındaki ilişkiyi belirlemek için korelasyon analizi yapılmıştır (Çizelge 4). Bu sonuçlara göre doğaya öykünme yaklaşımı ile yaratıcı tasarımlar üretmede en etkili faktör olarak, biçim üretme, daha sonra düşünceleri eskize aktarabilme ve problemlere yönelik farklı çözümler bulma olmuştur. En az ilişkili çıkan faktör ise çıkmaza girdiğinde yeni faktörler üretme çıkmıştır Ayrıca düşünceleri eskize aktarabilme-biçim üretebilme, çok yönlü düşünebilme-biçim üretebilme, problemlere uygun yeni çözümler bulma- biçim üretme kendi aralarında birbirleriyle en çok ilişkili kavramlar olarak belirlenmiştir

Çizelge 4. Yaratıcılığın ilişkili olduğu kavramlar
(1)Eskize aktarma
$0,48^{*} \quad 0,57^{* *}$
(2)Biçim üretme

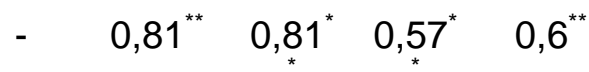
(3)Probleme uygun yeni çözümler bulma
- $\quad 0,7^{* *} \quad 0,56^{*} \quad 0,66^{* *}$
(4)Çok yönlü düşünme
$\begin{array}{ll}-\quad 0,37^{*} & 0,57^{* *}\end{array}$
(5)Çıkmaza girdiğinde yeni çözüm üretme
- $0,69^{* *}$
(6)Tasarım sürecini rahat-çabuk-akıcı
tamamlama
Yaratıcı-özgün tasarım üretme
$0,85^{*}, \underset{*}{087^{*}}$
$0,84^{* *}$
$0,79^{*}$
$0,54^{*}$
$0,6^{\star \star}$ $\begin{array}{ccc}1 & 2 & 3 \\ - & 0,84^{*} & 0,81^{* *}\end{array}$

$4,73^{\star}$

$5 \quad 6$

**. Korelasyon 0.01 seviyesinde önemlidir (2-tailed). 


\section{SONUÇ VE ÖNERILER}

Kullanıcının intiyaç ve gereksinimlerine yanıt veren mekânlar yaratmayı amaçlayan Peyzaj Mimarlığı disiplini için eğitim sürecinin nasıl olması gerektiği günümüzde hala tartışma konusudur. Tasarım ve yaratıcılık süreçlerini içeren tüm disiplinlerde olduğu gibi Peyzaj Mimarlığı eğitim programlarında da öğrenciye tasarım ve yaratıcılık becerisi kazandırmaya yönelik üslup ve yöntemler oldukça önemlidir. Bu bağlamda araştırmacılar, doğaya öykünme yaklaşımını, yeni bilgilerin edinilmesini destekleyen ve öğrenmeye yardımcı olan bir bilişsel süreç olduğunu savunmaktadır (Hofstadter, 2001; Casakin ve Timmeren van, 2015). Aynı zamanda doğaya öykünme yaklaşımı ile tasarım probleminin daha kolay (Dunbar ve Blachette, 2001; Ball et al. 2004; Ball and Christensen, 2009) ve yaratıcı bir şekilde çözümlenebileceğini savunmaktadırlar (Kowaltowski vd., 2010).

$\mathrm{Bu}$ çalışmada öğrencilerin yaratıcılık yönlerini geliştirmeyi amaçlayan doğaya öykünme seçmeli dersinin faydaları ortaya konmuştur. Bu dersi alan öğrenciler doğadan nasıl esinleneceklerini, nasıl örnek seçeceklerini öğrendikten sonra;

- Düşündükleri yaratıcı fikirleri daha kolay eskize aktarabilmişlerdir

- Tasarım sürecinde etkinliğe göre farklı-yeni biçim üretmeleri kolaylaşmıştır

- Probleme yönelik tek bir çözüm üretmek yerine, farklı açılardan bakıp çıkmaza girdiğinde değişiklik yapabilmeleri kolaylaşmıştır.

- Tasarım yapma süresi azalmış, kısa sürede daha yaratıcı ve kolay tasarımlar yapmalarını sağlamıştır.

Doğaya öykünme yaklaşımı ile tasarım sürecine başlayan öğrenciler, bu süreci daha iyi şekilde anlamakta ve tamamlamaktadırlar. Böylelikle hem öğrenciyken proje derslerinde yaptıkları tasarımlar hem de mezun olduktan sonra yapacakları açık mekân tasarımlarında, nasıl kendilerine özgü farklı ürünler ortaya koyabilecekleri öğretilmiş olur. Dolayısıyla kimliksiz, birbirleriyle aynı ve monoton açık mekân tasarımlarına neden olan sorunların çözümüne katkı sağlayan bir eğitim anlayışı ortaya konmuştur. Bu çalışmanın sonuçları hem yaratıcı tasarım sürecini öğrencilere daha iyi bir şekilde öğretmek isteyen eğitimciler için hem de farklı, kimlikli kentsel mekanlar üretmek isteyen tasarımcılar için faydalı olabilir.

Sonuç olarak; sadece seçmeli derslerde değil Çevre Tasarım ve Proje dersleri gibi önemli zorunlu derslerde de öykünme yaklaşımı kullanılmalıdır. Doğaya öykünme yaklaşımı; tasarım eğitimi veren mimarlık, çevre tasarımı, endüstriyel tasarım, iç mimarlık vb. bölümlerde de kullanılmalı,tasarım öğrencileri bu konuda bilgilendirilmelidir.

\section{KAYNAKÇA}

Abra, J,. The Motives for Creative Work, Hampton Press, Cresskill, New Jersey, USA 1997.

Alexander, C., Notes on the Synthesis of Form, Harvard University Press, Oxford 1964.

Anderson, J., Basics Architecture 03: Architectural Design. Switzerland: AVA Publishing SA 2011.

Apaydın, B., Eğitimci Gözüyle Tasarımda Yaratıcılık Söylemi. The Turkish Online Journal of Design, Art and Communication. 5(3), 2015,s.12-21.

Arslan, S., Sorguç, A., Mimarlık Tasarımı Paradigmasında Biomimesis'in Etkisi. Gazi Üniversitesi Mühendislik-Mimarlık Fakültesi Dergisi, 22(2), 2007, s. 451-459.

Asimow, A., Introduction to Design, Prentie-Hall, New York 1962. 
Ayıran, N., Mimari Tasarlama Sürecine ve Yapma Çevrenin İnsan ve Toplum Üzerindeki Etkilerine Yaratıcılık Bakış Açısından Bir Yaklaşım, Doktora Tezi, iTÜ Mimarlık Fakültesi.1983.

Ball, L.J., Christensen, B.T. Analogical Reasoning And Mental Simulation In Design: Two Strategies Linked To Uncertainty Resolution. Design Studies, 30, 2009, s.169- 186.

Ball, L.J., Ormerod, T.C., Morley, N.J. Spontaneous Analogising İn Engineering Design: A Comparative Analysis Of Experts And Novices. Design Studies, 25,2004, s. 495-508.

Bayazıt, N., Endüstri Ürünlerinde ve Mimarlıkta Tasarlama Metotlarına Giriş, Literatür Yayıncılık, İstanbul, Türkiye, 1994.

Best,G., Method and Intention in Architectural Design, Design Methods in Architecture, Lund Humphries. 1969.

Biomimicry Guild, Innovation Inspired by Nature Work Book. Biomimicry Guild, April, 2007.

Casakin H. P. Factors of Metaphors in Design Problem-solving: Implications for Design Creativity. International Journal of Design, 1, 2007, s. 21-33.

Casakin, H., Timmeren van, A. Analogies as Creative Inspiration Sources in the Design Studio: The Teamwork. Athens Journal of Architecture, 1(1), 2015, s.51-63.

Chiu, I., Shu, L.H. Biomimetic Design Through Natural Language Analysis to Facilitate Cross-Domain Information Retrieval. Artificial Intelligence for Engineering Design. 21, 2007, S. $45-59$.

Çubukcu, E., Gökçen Dündar, Ş., Can Creativity be Taught? An Empirical Study on Benefits of Visual Analogy in Basic Design Education. ITU A|Z, 4(2),2007, s. 67-80.

Dunbar, K., Blanchette, I., The in vivo/ in Vitro Approach to Cognition: The Case of Analogy, Trends in Cognitive Sciences, 5, 2001, s.334-339.

Emmanuel, E., Le Duc, V., The Architectural Theory of Viollet-le-Duc: Readings and Commentary. MIT Press, 1990.

Hagan, S. Taking Shape: A New Contact between Architecture and Nature, Architectural Press, 2001.

Hofstadter, D.R., Epilogue: Analogy as the core of cognition. In D. Gentner, K. L. Holyoak, \& B. N. Kokinov, (Eds.). The Analogical Mind : Perspectives from Cognitive Science (s.499538) Cambridge: MIT Press. 2001.

Kahvecioğlu, N.P, Mimari Tasarım Eğitiminde Bilgi ve Yaratıcılık Etkileşimi, İstanbul Teknik Üniversitesi, Doktora Tezi, 2001, s. 1-247

Kellert, S.,R., Building for Life: Designing and Understanding the Human-Nature Connection, Island Press, Washington, DC.2005. 
Kowaltowski D.C.C.K., Bianchi G.,Vale'ria Teixeira de Paiva, Methods that may Stimulate Creativity and Their Use in Architectural Design Education. International Journal of Technology Design Education, 20, 2010, s.453-476.

Melikoğlu Eke, A.S., Birbirini Yaratan Bir Triloji: Kavram-Düşünme-Tasarlama. I. Ulusal İç Mimari Tasarım Sempozyumu. Ekim 2015,s. 219-225.

Newell, A., Simon, H., Human Problem Solving. Englewood Cliffs, NJ: Prentice-Hall, 1972.

Önal, G.K., Yaratıcılık ve Kültürel Bağlamda Mimari Tasarım Süreci. Uludağ Üniversitesi Mühendislik-Mimarlık Fakültesi Dergisi, 16: 1, 2011, s. 155-162

Öncü, T. Torrance Yaratıcı Düşünme Testleri-Şekil Testi Aracılığıyla 12-14 Yaşları Arasındaki Çocukların Yaratıcılık Düzeylerinin Yaş ve Cinsiyete Göre Karşılaştırılması, Ankara Üniversitesi Dil ve Tarih Coğrafya Fakültesi Dergisi, 43.1, 2003, s. 221-237.

Özkan, D.G., Alpak, E.M., Düzenli, T. Tasarım Eğitiminde Yaratıcılığın Geliştirilmesi: Peyzaj Mimarlığı Çevre Tasarımı Stüdyo Çalışması. IJASOS- International E-Journal of Advances in Social Sciences, 4, 2016, s.136-143.

Öztürk, Ö.B. Günümüz Tasarım Eğitiminde Yöntem - Üslup Çekişmesi ve Sonuçları Üzerine Bir Deneme. International Conference on New Trends in Education and Their Implications, Antalya, 2010, S. 11-13.

Rodiek, J.E., Steiner, Special Issue: Landscape Architecture Research and Education. Landscape and Urban Planning, 42, 1998, s. 73-74.

Tunalı, İ, Sanat Ontolojisi, İnkılap Yayınları, İstanbul, 2002.

Uzunarslan, Ş., Polatkan,I., İç Mimari Tasarım Eğitiminde Yaratıcılık Etkinlikleri. 1. Sanat ve Tasarım Eğitimi Sempozyumu, Ankara, 2011.

Webster's -Merriam Coll. Dictionary, Permissions Editor, Merriam-Webster Inc., Springfield, MA. 1999.

Weisberg, R.W. Creativity and Knowledge a Challenge to Theories. In R. J. Sternberg (Ed.). Handbook of Creativity. Cambridge: University Press. 2004, s. 297-312.

Yavuzer H.S., Yaratıcılık, Boğaziçi Üniversitesi, İstanbul, 1989, s.36.

Ziss, A., Gerçekliği Sanatsal Özümsemenin Bilimi Estetik, Şahan Y., De Yayınevi, İstanbul, 1984. 